\title{
Fear of COVID-19 Scale for Hospital Staff in Regional Hospitals in Mexico: a Brief Report
}

\author{
Benjamín García-Reyna ${ }^{1}$ - Gilberto Daniel Castillo-García ${ }^{2}$. \\ Francisco José Barbosa-Camacho ${ }^{3}$ - Guillermo Alonso Cervantes-Cardona ${ }^{4}$. \\ Enrique Cervantes-Pérez ${ }^{5}$. Blanca Miriam Torres-Mendoza ${ }^{6}$. \\ Clotilde Fuentes-Orozco ${ }^{3} \cdot$ Kevin Josue Pintor-Belmontes ${ }^{3}$. \\ Bertha Georgina Guzmán-Ramírez ${ }^{3}$ - Aldo Bernal-Hernández ${ }^{3}$. \\ Alejandro González-Ojeda ${ }^{3} \cdot$ Gabino Cervantes-Guevara $^{1,6,7}$
}

Accepted: 16 October 2020 / Published online: 4 November 2020

(C) Springer Science+Business Media, LLC, part of Springer Nature 2020, corrected publication 2021

\begin{abstract}
The presence of COVID-19 has had psychological consequences among health personnel; these include fear, anxiety, and depression. In the current study, we used the Fear of COVID-19 Scale (FCV-19S) to assess the response to fear within health staff in Mexico. This was a cross-sectional survey study in which we administered the Spanish version of the FCV-19S to hospital staff. The FCV-19S is a seven-item questionnaire that assesses the severity of fear caused by COVID-19. A total of 2860 participants -1641 female and 1218 male personnel from three hospitals-were included in the study. The internal reliability of the scale was good, with Cronbach's alpha of .902. A confirmatory factor analysis (CFA) was conducted on the seven items of the FCV-19S, showing good model fit $\left(\chi^{2}(7)=29.40, p<.001 ; \mathrm{CFI}=.99 ; \mathrm{TLI}=.99 ; \mathrm{RMSEA}=.03 ; \mathrm{SRMR}=.010 ; \mathrm{AIC}=\right.$ 71.40). We found a global FCV-19S mean score of $19.3 \pm 6.9$, with a significant difference in scores between women and men. Our survey shows a significantly higher level of fear in nursing and administrative personnel, which may be explained by the nursing staff being in close contact with infected patients and the administrative staff lacking understanding of the possible implications of the infection, compared with nonclinical hospital personnel. Our results are consistent with those of other researchers. We must remember that fear is a reaction and that we must be courageous enough to trust validated infection prevention practices to provide the highest standard of care, in the safest environment that we can, for as long as we can.
\end{abstract}

Keywords COVID-19 $\cdot$ Fear ofCOVID-19 Scale $\cdot$ Fear $\cdot$ Psychological distress $\cdot$ Fear assessment

The original version of this article was revised: The name of coauthor Aldo Bernal-Hernández was incorrectly given as Aldo Hernández-Bernal in this article as originally published.

Gabino Cervantes-Guevara

gabino_guevara@hotmail.com

Extended author information available on the last page of the article 
The severe acute respiratory syndrome coronavirus 2 (SARS-CoV-2) is responsible for the current coronavirus pandemic, named COVID-19 by the World Health Organization. A pandemic changes the entire environment of a population, creating psychological issues of stigmatization, fear, and discrimination, fueled by a lack of accurate and comprehensive information for the entire population (Rajkumar 2020). One of the most critical challenges in dealing with the pandemic is controlling the social response- the fear caused by the pandemic - because, as previous SARS and Ebola outbreaks have shown, fear exacerbates the damage caused by the disease itself (Guan et al. 2020).

Fear can be described as an adaptive response to the environment - a defense mechanism designed to improve the chance of survival (Steimer 2002). However, when fear is not well calibrated to the actual threat, it can be maladaptive. The origin of fear could be novelty; something that brings uncertainty to a familiar situation, such as a pandemic. When the fear is excessive, the effects may be detrimental at both the individual level (e.g., mental health problems, such as phobia and social anxiety), and the societal level (e.g., panic shopping or xenophobia). On the other hand, insufficient fear, such as ignoring government's measures to slow the spread of coronavirus or issuing reckless policies that ignore the risks, may also result in harm for individuals and society (Deacon and Maack 2008; Engelhard et al. 2015; Olatunji et al. 2011). Societal safety measures, such as mandatory lockdowns, have their uses in preventing the spread of infections, but when such safety measures are prolonged or excessively strict they can have negative consequences, including disruption of the economy and unemployment (Mertens et al. 2020).

As the COVID-19 outbreak increases, the wave of fear and worry also rises (Lin 2020). The first research on the effect of this outbreak on the population is from China. Wang and collaborators published a study of 1210 persons in the general population, using the Depression, Anxiety and Stress Scale - 21 (DASS-21) scale to identify and screen for symptoms of depression, anxiety and stress, and the Impact of Event Scale-Revised (IES-R), which evaluates the impact of catastrophic events on the population and the development of post-traumatic stress syndrome. Among its results, the prevalence of $6.5 \%$ of moderate to severe depressive symptoms, $28.8 \%$ mild to severe anxiety symptoms, and $8.1 \%$ mild to severe stress, stand out (Wang et al. 2020). In China, this effect has also been studied in patients in isolation, medical and nursing personnel, and the general public, with the presence of high levels of stress and anxiety being the common denominator (Li et al. 2020; Lu et al. 2020; Xiao et al. 2020).

As previously mentioned, the general population is affected by fear, mandatory confinement, and the stress that accompanies this pandemic; health personnel on the front line of care also have challenges to face. By the end of September, Mexico currently has 726,431 confirmed cases, and the region of focus for this study (Guadalajara) has registered 26, 090 cases (Gobierno de México 2020). An increase in the number of confirmed cases, combined with the absence of protective equipment, long working hours, isolation of health personnel from their families and loved ones, and the fear of contagion, could translate into a high frequency of depression, suicidal ideation, suicide attempts, anxiety, substance abuse, and labor burnout (Lai et al. 2020; Mamun and Griffiths 2020; Pfefferbaum and North 2020; Shrivastava and Shrivastava 2020).

The risk of acquiring an infection is intrinsic in health care; it always has been and, for the foreseeable future, it will continue to exist. Therefore, effective infection prevention practices are paramount both to ensuring safety and combatting fear. However, in the face of the COVID-19 pandemic, deviations in proven preventive measures and standard care are common. Variations in personal protective equipment (PPE) use (e.g., utilizing N95 respirators for minimal risk encounters) and deferring critical, life-saving procedures (because of lack of 
confidence in validated diagnostic test performance or PPE efficacy) increase the overall risk to health-care workers (HCW) and patients alike. The reason these variations exist must be explored, and we postulate fear as a significant factor.

There are many valid reasons for developing fear in this pandemic; the fear of developing infection, fear of failing to provide adequate care for patients given limited resources, fear of carrying the virus home and infecting family and friends, fear of stigmatization, and many others. Fear is not exclusive to the COVID-19 pandemic; it has been well described in other infectious disease epidemics, including HIV and SARS. Ho et al. noted that fear in HCW during SARS was significant. More than half of HCW perceived that complying with or maintaining infection prevention practices gave them little control over becoming infected. High stress, heavy workload, and sudden changes in routine medical procedures during the SARS outbreak made it impossible for many HCW to fully implement preventive practices, even though they understood their purpose and the potential risk of not following them (Ho et al. 2005).

In response to the current contingency and its emotional repercussions, medical researchers around the world have devised ways to measure the impact using scales that focus on the stress response and fear (Pakpour et al. 2020a, b). Ahorsu et al. developed a scale to evaluate fear of the COVID-19 pandemic and its effects on the psychological mental state of the Iranian general population. After panel reviews and the corrected item-total correlation test, seven items with acceptable corrected item-total correlations were retained and further confirmed by significant and strong factor loads. The scale has high internal consistency and validity, supported by several other scales (Hospital Anxiety and Depression Scale and Perceived Vulnerability to Disease Scale), in assessing fear of COVID-19 among the general population. Numerous tests have found high internal consistency and robust psychometric properties in several languages (Alyami et al. 2020; Huarcaya-Victoria et al. 2020; Reznik et al. 2020; Sakib et al. 2020; Satici et al. 2020; Soraci et al. 2020; Winter et al. 2020). The scale will also be useful in calming COVID-19 fears among individuals.

Only a handful of studies have evaluated fear and mental health in the Mexican population. These report an increase in depression, anxiety, stress, and Internet addiction in the first months of the pandemic in the general population (Cortés-Álvarez et al. 2020; Garcia-Priego et al. 2020; Ramírez et al. 2020). Because the pandemic is an emerging problem, specific data on the impact on the mental health of health workers, and how it could affect the care and management of patients with COVID-19, is not yet available in Mexico. We believe it is essential to analyze the different attitudes of health personnel working in these conditions.

\section{Methods}

\section{Aims}

The aims were to identify the level of fear of COVID-19 in hospital staff working in the region of Guadalajara and determine any difference in level according to gender, age group, working category, hospital unit, and work shift.

\section{Design}

This was a cross-sectional survey study that evaluated the fear of COVID-19 using the Fear of COVID-19 Scale (FCV-19S) (Ahorsu et al. 2020). The validated Spanish language version of 
the FCV-19S (Huarcaya-Victoria et al. 2020) was used. In addition, we asked about the participants' gender, age, working category, hospital unit, and work shift.

\section{Instrument}

The FCV-19S is a questionnaire that evaluates fear of the global pandemic caused by the SARS-CoV-2. The FVC-19S consists of seven items, such as "It makes me uncomfortable to think about coronavirus-19," "I am afraid of losing my life because of coronavirus-19," and "When watching news and stories about coronavirus-19 on social media, I become nervous or anxious," each with a five-point Likert scale of options. The participant is instructed to choose the option that best represents their perception about the statement presented. The maximum possible total is 35 points. The scale's authors indicate that the higher the score is, the higher is the level of the participants' fear of COVID-19.

\section{Participants}

A total of 2930 participants were surveyed during April and May 2020. The participants were employees of three hospitals in the vicinity of the authors (Guadalajara's metropolitan area). These hospitals were contacted because they were the largest three (of a total of six) hospitals that had been converted to exclusive COVID-19 hospitals in Guadalajara. These hospitals were chosen because fear could be a prevalent condition in the hospitals' personnel, and because they are third-level hospitals, meaning they present all medical specialties needed to attend to any patient in the area. Physical copies of the survey were distributed to hospital staff. Inclusion criteria were being at least 18 years old and willing to participate in the study. The surveys were answered anonymously. The participants were categorized into four groups: Nursing personnel, medical personnel (including physicians and medical residents), administrative personnel (including archive, office, and administration personnel), and nonclinical hospital personnel with direct contact with COVID-19 (including laboratory, pharmacy, cleaning, kitchen, nutrition, radiology, security, and psychology personnel).

\section{Sample Size}

The sample size was calculated using StatCalc from Epi-info (Center for Disease Control, Atlanta, GA, USA), based on the total number of employees in the state delegation $(34,327)$. The hospitals surveyed had a total population of 9720. During a pilot survey, we analyzed 60 employees and found a $20 \%$ prevalence of fear when converting the FCV-19S to percentages. Inferring that the fear prevalence perceived by the hospital staff would be $20 \%$, with an error of $5 \%$ and a confidence level of $99.99 \%$, we calculated the minimum necessary number of surveys to be 942 . Our final sample included 2930 employees.

\section{Data Analysis}

The data were analyzed using SPSS software (version 23.0 for Windows; IBM SPSS, Armonk, NY, USA). Descriptive analyses included proportions, means, and standard deviations. The inferential analysis of categorical variables was performed using the chi-squared test, Fisher's exact probability test, or variance analysis, as appropriate. Student's $t$ test was used to analyze continuous variables. A probability level of $p<.05$ was considered significant. The internal reliability of the scale was good, 
with Cronbach's alpha of .902 . The FCV-19S items were analyzed using a confirmatory factor analysis (CFA) to determine the adequacy of the model within the sample using the following fit indices: root mean square error of approximation (RMSEA), standardized root mean squared residual (SRMR), Tucker Lewis Index (TLI), Confirmatory Fit Index (CFI), and Akaike's Information Criterion (AIC). The CFA model was performed using AMOS software (version 24.0 for Windows; IBM SPSS, Armonk, NY, USA).

\section{Results}

Of the 2930 surveys, 70 were excluded for being incomplete. A total of 2860 participants were included in the study. The sample's demographic information can be found in Table 1 . The global FCV-19S mean score was $19.3 \pm 6.9$ (median =19). An independent-samples $t$ test was conducted to compare the SC-19S scores between women $(19.81 \pm 6.77)$ and men $(18.71 \pm$ $7.19)$ and found a significant difference $(t(2858)=-4.20, p<.001)$. Additionally, an independent-samples $t$ test was conducted to compare the fear scores in both sexes by each of the scale's items. The mean scores and differences can be found in Table 2.

Across work categories, the group with the highest fear score was nursing personnel (NP) $(19.5 \pm 6.8)$, followed by administrative personnel (AP) $(19.39 \pm 7.5)$, medical personnel (MP) (19.35 \pm 6.8 ), and nonclinical hospital personnel in direct contact with COVID-19 (HP) (18.9 \pm 6.9 ). A one-way between-group ANOVA was conducted to compare the fear scores but did not find any significant effect of the four work categories on fear $(F(3,2856)=.866, p>.5)$. Each scale item's individual score by work category can be found in Table 3 . Finally, one-way between-group ANOVA was conducted to compare the fear scores across work shifts and hospital units. There was no significant effect of work shift on fear score $(F(3,2856)=.400$, $p>.5)$. However, there was a significant effect of hospital units on fear score $(F(2,2856)=$

Table 1 Demographic characteristics of the sample

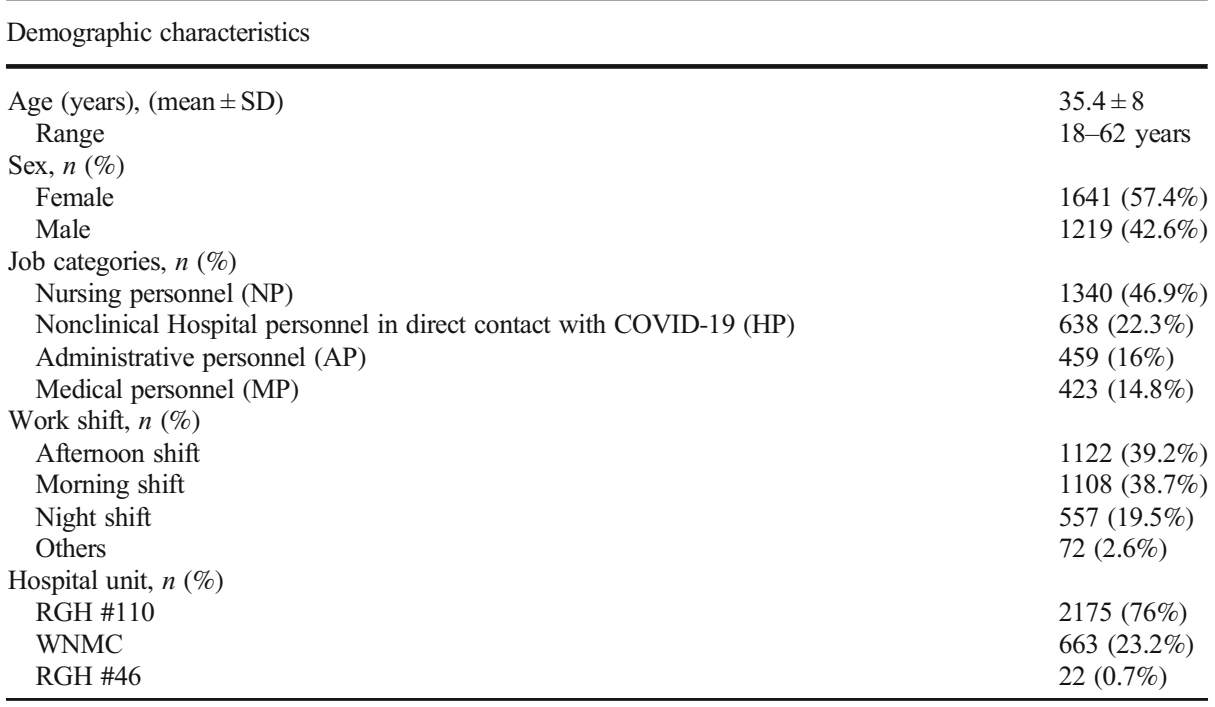

Abbreviations: RGH Regional General Hospital, WNMC Western National Medical Center 
Table 2 FCV-19S scores by gender

\begin{tabular}{lrrl}
\hline FCV-19S items & $\begin{array}{l}\text { Female } \\
\text { mean scores }\end{array}$ & \multicolumn{1}{l}{$\begin{array}{l}\text { Male mean } \\
\text { scores }\end{array}$} \\
\hline 1. I am most afraid of coronavirus-19 & $3.25 \pm 1.20$ & $3.07 \pm 1.24$ & $-3.88^{* * *}$ \\
2. It makes me uncomfortable to think about coronavirus-19 & $3 \pm 1.21$ & $2.89 \pm 1.26$ & $-2.49^{*}$ \\
3. My hands become clammy when I think about coronavirus-19 & $2.34 \pm 1.16$ & $2.28 \pm 1.23$ & -1.29 \\
4. I am afraid of losing my life because of coronavirus-19 & $3.18 \pm 1.35$ & $3.01 \pm 1.36$ & $-3.17^{* *}$ \\
5. When watching news and stories about coronavirus-19 on social & $2.90 \pm 1.25$ & $2.62 \pm 1.24$ & $-5.92^{* * *}$ \\
media, I become nervous or anxious & & & \\
6. I cannot sleep because I am worrying about getting coronavirus-19 & $2.45 \pm 1.22$ & $2.35 \pm 1.25$ & $-2.16^{*}$ \\
7. My heart races or palpitates when I think about getting & $2.66 \pm 1.24$ & $2.45 \pm 1.28$ & $-4.34^{* * *}$ \\
$\quad$ coronavirus-19 & & &
\end{tabular}

Notes: $*: p$ value $<.05, * *: p$ value $<.010, * * *: p$ value $<.001$

$10.40, p<.001)$. Post hoc comparisons using Tukey honestly significant difference test indicated that the mean scores for the Regional General Hospital (RGH) \#110 (19.67 \pm 6.95$)$ were significantly different from those of the Western National Medical Center (WNMC) (18.29 \pm 6.99$)$. However, the scores of RGH \#46 (18.19 \pm 5.34$)$ did not significantly differ from those of other hospital units.

CFA was conducted on the seven items of the FCV-19S. The item loadings ranged from .64 to .88 . The model fit indexes were $\chi^{2}(7)=29.40, p<.001$; CFI $=.99$; TLI $=.99$; RMSEA $=$ $.03 ; \mathrm{SRMR}=.010 ; \mathrm{AIC}=71.40$. The CFA component factor loadings can be found in Table 4.

\section{Discussion}

Currently, the COVID-19 pandemic is arguably the most significant health problem we are facing globally. Most of the efforts that have been made in research to date, by both public and

Table 3 Global and working categories FCV-19S mean scores

\begin{tabular}{llllll}
\hline FCV-19S items & $\begin{array}{l}\text { NP mean } \\
\text { scores }\end{array}$ & $\begin{array}{l}\text { MP mean } \\
\text { scores }\end{array}$ & $\begin{array}{l}\text { HP mean } \\
\text { scores }\end{array}$ & $\begin{array}{l}\text { AP mean } \\
\text { scores }\end{array}$ & $\begin{array}{l}\text { Total } \\
\text { sample } \\
\text { mean } \\
\text { scores }\end{array}$ \\
\hline $\begin{array}{l}\text { 1. I am most afraid of coronavirus-19 } \\
\text { 2. It makes me uncomfortable to think } \\
\text { about coronavirus-19 }\end{array}$ & $3.19 \pm 1.22$ & $3.24 \pm 1.18$ & $3.08 \pm 1.17$ & $3.21 \pm 1.30$ & $3.18 \pm 1.22$ \\
$\begin{array}{l}\text { 3. My hands become clammy when I think } \\
\text { about coronavirus-19 }\end{array}$ & $2.34 \pm 1.18$ & $2.22 \pm 1.19$ & $2.34 \pm 1.17$ & $2.32 \pm 1.24$ & $2.32 \pm 1.19$ \\
$\begin{array}{l}\text { 4. I am afraid of losing my life because of } \\
\text { coronavirus-19 }\end{array}$ & $3.15 \pm 1.36$ & $3.27 \pm 1.32$ & $2.99 \pm 1.36$ & $2.98 \pm 1.38$ & $3.11 \pm 1.36$ \\
$\begin{array}{l}\text { 5. When watching news and stories about } \\
\text { coronavirus-19 on social media, I be- } \\
\text { come nervous or anxious }\end{array}$ & $2.81 \pm 1.23$ & $2.79 \pm 1.24$ & $2.36 \pm 1.28$ & $2.79 \pm 1.32$ & $2.78 \pm 1.26$ \\
$\begin{array}{l}\text { 6. I cannot sleep because I am worrying } \\
\text { about getting coronavirus-19 }\end{array}$ & $2.43 \pm 1.22$ & $2.35 \pm 1.22$ & $2.37 \pm 1.20$ & $2.46 \pm 1.32$ & $2.41 \pm 1.23$ \\
$\begin{array}{l}\text { 7. My heart races or palpitates when I } \\
\text { think about getting coronavirus-19 }\end{array}$ & $2.57 \pm 1.23$ & $2.57 \pm 1.27$ & $2.56 \pm 1.24$ & $2.56 \pm 1.36$ & $2.57 \pm 1.26$ \\
\hline
\end{tabular}

Abbreviations: $N P$ nursing personnel, $M P$ medical personnel, $A P$ administrative personnel, $H P$ nonclinical hospital personnel with direct contact with COVID-19 
Table 4 CFA correlations and factor loadings

1. I am most afraid of coronavirus- 19

2. It makes me uncomfortable to think about coronavirus-19

3. My hands become clammy when I think about coronavirus-19

4. I am afraid of losing my life because of coronavirus-19

5. When watching news and stories about coronavirus-19 on social media, I become $\quad 0.88$ nervous or anxious

6. I cannot sleep because I am worrying about getting coronavirus-19

0.78

7. My heart races or palpitates when I think about getting coronavirus-19

0.76

private organizations, have explored the pathophysiological effects of the virus on health or sought therapeutic alternatives so that the health personnel at the forefront of the epidemic have the best tools to face the problem. The effects of the pandemic on the mental health of hospital workers should not be overlooked, yet comparatively few authors have addressed the problem that the pandemic represents for public health and the mental health of this section of the population.

An online survey in May 2020 by Soraci et al. in Italy, one of the most affected countries, administered the Italian versions of the FCV-19S, the Hospital Anxiety and Depression Scale (HADS), and the Severity Measure for Specific Phobia-Adult (SMSP-A) to 249 participants (Soraci et al. 2020). Our results differ considerably from those of Soraci et al.; however, the sample used by those authors did not represent an equal distribution of population-92\% (229 out of 249) of their participants were female-while our sample comprised $57.4 \%$ (1641) females and $42.6 \%$ (1219) males. The FCV-19S fear severity scores reported by in the Italian general population were lower than in our sample (16.8 vs. 19.2). Although no formal diagnoses concerning mood disorders were obtained in the study by Soraci et al., scores on the FCV-19S were significantly and positively related to scores assessing depression and anxiety (HADS) and the severity of the specific phobia (SMSP-A). The validity of the FCV19S was supported by significant and positive correlations with the HADS and SMSP-A.

Like Soraci et al., Satici et al. adapted the FCV-19S to Turkish and applied it to 1304 participants using online surveys. Data analysis revealed significant positive correlations between the FCV-19S and depression, anxiety, and stress. The fear of COVID-19 was found to be associated with psychological distress and life satisfaction (Satici et al. 2020). Correspondingly, Reznik et al. applied the FCV-19S to a sample of 850 participants from Russia and Belarus. Their reported mean fear score was lower than in our sample (17.2 vs. 19.2), but both studies reported higher levels of fear in female than in male participants (Reznik et al. 2020).

Our study had the second largest population, with a total sample of 2860 participants, and as far as we know, this is the first time the FCV-19S has been applied in a hospital setting and as a direct personal questionnaire; other studies have used online surveys. Furthermore, we decided to analyze the relationship between the different job categories and their levels of fear. The CFA model proves that the inventory is useful when exploring the fear prevalence in the general and medical population. Our analysis presented similar fitness to the overall fitness described by Sakib et al. (2020) and Satici et al. (2020).

Fear can alter the cognitive function of those who suffer from it, by affecting memory, focus, attention, and decision-making (McEwen and Morrison 2013). Reports show that after the SARS pandemic of 2003, survivors were diagnosed with post-traumatic stress disorder, depression, anxiety disorders, and in some cases, obsessive-compulsive disorder up to 4 years 
later (Lam et al. 2009). In the COVID-19 crisis, HCW are expected to perceive a high amount of stress due to the overall lack of preparation, infrastructure, and PPE (Chua et al. 2004; Maunder et al. 2003; Pfefferbaum and North 2020). In 2003, the stress of the pandemic caused abandonment of work and a staff deficit in many hospitals in China and Taiwan. Many HCW opted not to stay in their own homes, so they did not transmit the disease to their families and loved ones, and in some extreme cases, their families physically blocked them from leaving their houses (Chan 2003; Tzeng 2003).

It is interesting to note that the hospitals' administrative personnel, while not interacting directly with COVID-19 patients, still presented higher scores than medical staff and other personnel who interacted directly with infected patients. This difference was not statistically significant. It could be theorized that medical personnel have more in-depth knowledge of the disease and the outcomes than the general population. These results are similar to those of Li et al., who found there were higher levels of vicarious traumatization in the general population than in front-line nursing personnel ( $\mathrm{Li}$ et al. 2020). As expected, the nursing personnel presented the highest scores of fear of COVID-19, as their role as primary front-line personnel includes direct interaction with patients in a wide range of activities and areas. However, in the studies by Soraci et al. and Reznik et al., the general population presented lower fear severity than our HCW sample. This could be because our personnel were exposed to COVID-19 patients on a daily basis, whereas the general population could be protected from infection by following the correct quarantine and preventive recommendations. Nonetheless, our medical and nursing personnel sample still did not present high scores in the FCV-19S. This could be due to a low incidence of COVID-19 in Jalisco, Mexico during the recruitment period for the study; as of May 31, only 2289 confirmed cases had been reported in the state (Secretaría de Salud 2020).

Many external situations have increased the existing stress levels in an already altered mental health situation for hospital personnel; HCW not only had to face fear of contagion or infecting their families and loved ones, but also confrontations with the general population. In addition to the inherent stress of the pandemic, Mexican public health institutions have reported more than 47 "fear of contagion" attacks on staff, leading to a request for support from the federal government to safeguard the well-being of HCW (IMSS 2020). Likewise, physical and verbal attacks against health personnel have been reported, including having disinfectants and boiling beverages thrown towards them, and being denied the use of public transport, reporting these attacks in more than 11 health-care facilities (Rueda 2020). Police officers have also been the victims of such aggression when trying to break up events that threaten public health. They have been attacked on numerous occasions, including one case in which 10 policemen, who intervened at an event near the capital in the course of their duties, were seriously assaulted (Fernández 2020).

Strategies for addressing fear in such situations include targeted education, system-wide communication to avoid disparities in understanding, leveraging the call for altruism, emphasizing a sense of civic duty, encouraging colleagues to support each other, and encouraging those with a low fear threshold to seek available mental health support.

One of the study limitations is that there were no other scales used alongside the FCV-19S to construct the validity of the scale in our sample, so a complete validation of the scale could not be achieved. Nonetheless, as no other studies have reported the prevalence of fear in Mexico, our study can provide some understanding. Another limitation is that the study was performed at the beginning of the pandemic, when the study region had 6000 cases; Jalisco by the end of September has 26,000 confirmed cases. New studies should be carried out to analyze the evolution of the severity of COVID-19 fear in hospital personnel. The study was 
performed on hospital personnel, so the results cannot be extrapolated to the general population, as the intrinsic characteristics of each population are fundamentally different. Additionally, there are no other studies on the prevalence of COVID-19 fear in health-care professionals using this scale. This may also be a strength, as this study may now provide a stepping stone for further studies on how fear in hospital staff changes in response to pandemic changes and for the development of coping and prevention tools to keep health-care personnel physically and mentally healthy. Further studies using the FCV-19S and other scales could strengthen the scale validity in Spanish-speaking countries.

Fear is a commonplace with the COVID-19 pandemic. HCW are not immune to anxiety and fear and, in fact, may suffer higher rates of fear than others (Cawcutt et al. 2020). We must address the psychological impact of facing COVID-19 to further mitigate the spread of infection. We must remember that fear is a reaction, and that we must be courageous enough to trust validated infection prevention practices to provide the highest standard of care, in the safest environment that we can, for as long as we can. Choose courage.

\section{Conclusions}

Although the fear levels in our study were lower than in other populations, it had already had effects on the health staff. Our findings show significantly higher levels of fear in females and in nursing and administrative personnel, which may be explained by the nursing staff being in closer contact with infected patients and by administrative staff lacking understanding of the possible implications of the infection compared with health-care personnel. The FCV-19S is a scale that shows validity and reliability in assessing fear of COVID-19 in our population. Our results are consistent with those of other researchers.

\section{Compliance with Ethical Standards}

Conflict of Interest All authors declare that they have no conflict of interest.

Informed Consent All procedures followed were in accordance with the ethical standards of the responsible committee on human experimentation (institutional and national) and with the Helsinki Declaration of 1975, as revised in 2000 (5). Informed consent was obtained from all patients for being included in the study. The National Ethics Committee authorized the study protocol with the registration number: R-2020-785-006.

\section{References}

Ahorsu, D. K., Lin, C., Imani, V., Saffari, M., Griffiths, M. D., \& Pakpour, A. H. (2020). The fear of COVID-19 scale: development and initial validation. International Journal of Mental Health \& Addiction, 1-9.

Alyami, M., Henning, M., Krägeloh, C. U., \& Alyami, H. (2020). Psychometric evaluation of the Arabic version of the fear of COVID-19 scale. International Journal of Mental Health \& Addiction, 1-14. https://doi. org/10.1007/s11469-020-00316-x.

Cawcutt, K. A., Starlin, R., \& Rupp, M. E. (2020). Fighting fear in healthcare workers during the COVID-19 pandemic. Infection Control and Hospital Epidemiology, 41(10), 1192-1193. https://doi.org/10.1017 ice.2020.315.

Chan, S. (2003). Nurses fighting against severe acute respiratory syndrome (SARS) in Hong Kong. Journal of Nursing Scholarship, 35(3), 209-209. https://doi.org/10.1111/j.1547-5069.2003.00209.x.

Chua, S. E., Cheung, V., Cheung, C., McAlonan, G. M., Wong, J. W. S., Cheung, E. P. T., Chan, M. T. Y., Wong, M. M. C., Tang, S. W., Choy, K. M., Wong, M. K., Chu, C. M., \& Tsang, K. W. T. (2004). 
Psychological effects of the SARS outbreak in Hong Kong on high-risk health care workers. Canadian Journal of Psychiatry, 49(6), 391-393. https://doi.org/10.1177/070674370404900609.

Cortés-Álvarez, N. Y., Piñeiro-Lamas, R., \& Vuelvas-Olmos, C. R. (2020). Psychological effects and associated factors of COVID-19 in a Mexican sample. Disaster Medicine \& Public Health Preparedness, 1-12. https://doi.org/10.1017/dmp.2020.215.

Gobierno de México. (2020). Mapa Interactivo COVID-19 en México [Interactive map of COVID-19 in Mexico]. Secretaría de Salud. https://covid19.sinave.gob.mx/

Deacon, B., \& Maack, D. J. (2008). The effects of safety behaviors on the fear of contamination: an experimental investigation. Behaviour Research and Therapy, 46(4), 537-547. https://doi.org/10.1016/j.brat.2008.01.010.

Engelhard, I. M., van Uijen, S. L., van Seters, N., \& Velu, N. (2015). The effects of safety behavior directed towards a safety cue on perceptions of threat. Behavior Therapy, 46(5), 604-610. https://doi.org/10.1016/j. beth.2014.12.006.

Fernández, E. (2020). Agreden a personal del municipio de Ecatepec por impedir fiesta ante Covid-19. [Ecatepec municipality staff attacked for preventing party before Covid-19]. El Universal. https:/www.eluniversal. com.mx/metropoli/agreden-personal-del-municipio-de-ecatepec-por-impedir-fiesta-ante-covid-19

Garcia-Priego, B. A., Triana-Romero, A., Pinto-Galvez, S. M., Duran-Ramos, C., Salas-Nolasco, O., Reyes, M. M., de la Medina, A. R., \& Troche, J. M. R. (2020). Anxiety, depression, attitudes, and internet addiction during the initial phase of the 2019 coronavirus disease (COVID-19) epidemic: a cross-sectional study in Mexico. MedRxiv, 2020(05), 10.20095844. https://doi.org/10.1101/2020.05.10.20095844.

Guan, W., Ni, Z., Hu, Y., Liang, W., Ou, C., He, J., Liu, L., Shan, H., Lei, C., Hui, D. S. C., Du, B., Li, L., Zeng, G., Yuen, K.-Y., Chen, R., Tang, C., Wang, T., Chen, P., Xiang, J., et al. (2020). Clinical characteristics of coronavirus disease 2019 in China. New England Journal of Medicine, 382(18), 1708-1720. https://doi. org/10.1056/NEJMoa2002032.

Ho, S. M. Y., Kwong-Lo, R. S. Y., Mak, C. W. Y., \& Wong, J. S. (2005). Fear of severe acute respiratory syndrome (SARS) among health care workers. Journal of Consulting \& Clinical Psychology, 73(2), 344 349. https://doi.org/10.1037/0022-006X.73.2.344.

Huarcaya-Victoria, J., Villarreal-Zegarra, D., Podestà, A., \& Luna-Cuadros, M. A. (2020). Psychometric properties of a Spanish version of the fear of COVID-19 scale in general population of Lima, Peru. International Journal of Mental Health \& Addiction, 1. https://doi.org/10.1007/s11469-020-00354-5.

IMSS. (2020). En el IMSS se garantiza la seguridad de inmuebles, personas y bienes ante emergencia sanitaria por COVID-19 | Sitio Web 'Acercando el IMSS al Ciudadano.' Gobierno de México. http://www.imss.gob. $\mathrm{mx} / \mathrm{prensa} /$ archivo/202004/228

Lai, J., Ma, S., Wang, Y., Cai, Z., Hu, J., Wei, N., Wu, J., Du, H., Chen, T., Li, R., Tan, H., Kang, L., Yao, L., Huang, M., Wang, H., Wang, G., Liu, Z., \& Hu, S. (2020). Factors associated with mental health outcomes among health care workers exposed to coronavirus disease 2019. JAMA Network Open, 3(3), e203976. https://doi.org/10.1001/jamanetworkopen.2020.3976.

Lam, M. H. B., Wing, Y. K., Yu, M. W. M., Leung, C. M., Ma, R. C. W., Kong, A. P. S., So, W. Y., Fong, S. Y. Y., \& Lam, S. P. (2009). Mental morbidities and chronic fatigue in severe acute respiratory syndrome survivors: long-term follow-up. Archives of Internal Medicine, 169(22), 2142-2147. https://doi.org/10.1001 /archinternmed.2009.384.

Li, Z., Ge, J., Yang, M., Feng, J., Qiao, M., Jiang, R., Bi, J., Zhan, G., Xu, X., Wang, L., Zhou, Q., Zhou, C., Pan, Y., Liu, S., Zhang, H., Yang, J., Zhu, B., Hu, Y., Hashimoto, K., Jia, Y., Wang, H., Wang, R., Liu, C., \& Yang, C. (2020). Vicarious traumatization in the general public, members, and non-members of medical teams aiding in COVID-19 control. Brain, Behavior, and Immunity., 88, 916-919. https://doi.org/10.1016/j. bbi.2020.03.007.

Lin, C.-Y. (2020). Social reaction toward the 2019 novel coronavirus (COVID-19). Social Health \& Behavior, 3(1), 1. https://doi.org/10.4103/shb.shb_11_20.

Lu, W., Wang, H., Lin, Y., \& Li, L. (2020). Psychological status of medical workforce during the COVID-19 pandemic: a cross-sectional study. Psychiatry Research, 288(March), 1-5. https://doi.org/10.1016/j. psychres.2020.112936.

Mamun, M. A., \& Griffiths, M. D. (2020). First COVID-19 suicide case in Bangladesh due to fear of COVID-19 and xenophobia: possible suicide prevention strategies. Asian Journal of Psychiatry, 51, 102073. https:/doi. org/10.1016/j.ajp.2020.102073.

Maunder, R., Hunter, J., Vincent, L., Bennett, J., Peladeau, N., Leszcz, M., Sadavoy, J., Verhaeghe, L. M., Steinberg, R., \& Mazzulli, T. (2003). The immediate psychological and occupational impact of the 2003 SARS outbreak in a teaching hospital. Canadian Medical Association Journal, 168(10), 1245-1251.

McEwen, B. S., \& Morrison, J. H. (2013). The brain on stress: vulnerability and plasticity of the prefrontal cortex over the life course. Neuron, 79(1), 16-29. https://doi.org/10.1016/j.neuron.2013.06.028.

Mertens, G., Gerritsen, L., Duijndam, S., Duijndam, S., \& Engelhard, I. M. (2020). Fear of the coronavirus (COVID-19): Predictors in an online study conducted in March 2020. https://doi.org/10.31234/osf.io/2p57j. 
Olatunji, B. O., Etzel, E. N., Tomarken, A. J., Ciesielski, B. G., \& Deacon, B. (2011). The effects of safety behaviors on health anxiety: an experimental investigation. Behaviour Research and Therapy, 49(11), 719728. https://doi.org/10.1016/j.brat.2011.07.008.

Pakpour, A. H., Griffiths, M. D., \& Lin, C. Y. (2020a). Assessing psychological response to the COVID-19: the fear of COVID-19 scale and the COVID stress scales. International Journal of Mental Health \& Addiction, 1-4. https://doi.org/10.1007/s11469-020-00334-9.

Pakpour, A. H., Griffiths, M. D., \& Lin, C. Y. (2020b). Assessing the psychological response to the COVID-19: a response to Bitan et al. 'Fear of COVID-19 scale: psychometric characteristics, reliability and validity in the Israeli population. Psychiatry Research, 290, 113127. https://doi.org/10.1016/j.psychres.2020.113127.

Pfefferbaum, B., \& North, C. S. (2020). Mental health and the COVID-19 pandemic. New England Journal of Medicine., 383, 510-512. https://doi.org/10.1056/nejmp2008017.

Rajkumar, R. P. (2020). COVID-19 and mental health: a review of the existing literature. Asian Journal of Psychiatry, 52, 102066. https://doi.org/10.1016/j.ajp.2020.102066.

Ramírez, L. P. G., Arriaga, R. J. M., Hernández-Gonzalez, M. A., \& De la Roca-Chiapas, J. M. (2020). Psychological distress and signs of post-traumatic stress in response to the COVID-19 health emergency in a Mexican sample. Psychology Research and Behavior Management, 13, 589-597. https://doi. org/10.2147/PRBM.S259563.

Reznik, A., Gritsenko, V., Konstantinov, V., Khamenka, N., \& Isralowitz, R. (2020). COVID-19 fear in Eastern Europe: validation of the fear of COVID-19 scale. International Journal of Mental Health \& Addiction, 12, 1-6. https://doi.org/10.1007/s11469-020-00283-3.

Rueda, R. (2020). Por COVID-19, lanzan cloro a médicos, los insultan, les niegan transporte público... El Financiero. https:/www.elfinanciero.com.mx/nacional/por-covid-19-lanzan-cloro-a-medicos-los-insultanles-niegan-transporte-publico

Sakib, N., Bhuiyan, A. K. M. I., Hossain, S., Al Mamun, F., Hosen, I., Abdullah, A. H., Sarker, M. A., Mohiuddin, M. S., Rayhan, I., Hossain, M., Sikder, M. T., Gozal, D., Muhit, M., Islam, S. M. S., Griffiths, M. D., Pakpour, A. H., \& Mamun, M. A. (2020). Psychometric validation of the Bangla fear of COVID-19 scale: confirmatory factor analysis and Rasch analysis. International Journal of Mental Health \& Addiction, 1-12. https://doi.org/10.1007/s11469-020-00289-x.

Satici, B., Gocet-Tekin, E., Deniz, M. E., \& Satici, S. A. (2020). Adaptation of the Fear of COVID-19 Scale: its association with psychological distress and life satisfaction in Turkey. International Journal of Mental Health \&Addiction, 1-9. https://doi.org/10.1007/s11469-020-00294-0.

Secretaría de Salud. (2020). Coronavirus (COVID-19)-Comunicado Técnico Diario 2020/05/26. https://www. gob.mx/salud/documentos/coronavirus-covid-19-comunicado-tecnico-diario-238449

Shrivastava, S., \& Shrivastava, P. (2020). COVID-19 pandemic: Responding to the challenge of global shortage of personal protective equipment. Social Health \& Behavior, 3(2), 70. https://doi.org/10.4103/shb. shb_17_20.

Soraci, P., Ferrari, A., Abbiati, F. A., Del Fante, E., De Pace, R., Urso, A., \& Griffiths, M. D. (2020). Validation and psychometric evaluation of the Italian version of the fear of COVID-19 scale. International Journal of Mental Health \& Addiction. https://doi.org/10.1007/s11469-020-00277-1.

Steimer, T. (2002). The biology of fear- and anxiety-related behaviors. Dialogues in Clinical Neuroscience, 4(3), 231-249.

Tzeng, H.-M. (2003). Fighting the SARS epidemic in Taiwan: a nursing perspective. Journal of Nursing Administration, 33(11), 565-567. https://journals.lww.com/jonajournal/Citation/2003/11000/Fighting_the_ SARS_Epidemic_in_Taiwan__A_Nursing.5.aspx

Wang, C., Pan, R., Wan, X., Tan, Y., Xu, L., McIntyre, R. S., Choo, F. N., Tran, B., Ho, R., Sharma, V. K., \& Ho, C. (2020). A longitudinal study on the mental health of general population during the COVID-19 epidemic in China. Brain, Behavior, \& Immunity, 87, 40-48. https://doi.org/10.1016/j.bbi.2020.04.028.

Winter, T., Riordan, B. C., Pakpour, A. H., Griffiths, M. D., Mason, A., Poulgrain, J. W., \& Scarf, D. (2020). Evaluation of the English version of the fear of COVID-19 scale and its relationship with behavior change and political beliefs. International Journal of Mental Health \& Addiction. https://doi.org/10.1007/s11469020-00342-9.

Xiao, H., Zhang, Y., Kong, D., Li, S., \& Yang, N. (2020). Social capital and sleep quality in individuals who selfisolated for 14 days during the coronavirus disease 2019 (COVID-19) outbreak in January 2020 in China. Medical Science Monitor, 26, e923921-1. https://doi.org/10.12659/MSM.923921.

Publisher's Note Springer Nature remains neutral with regard to jurisdictional claims in published maps and institutional affiliations. 


\section{Affiliations}

Benjamín García-Reyna ${ }^{1}$ • Gilberto Daniel Castillo-García ${ }^{2}$ • Francisco José Barbosa-Camacho $^{3}$ - Guillermo Alonso Cervantes-Cardona ${ }^{4} \cdot$ Enrique Cervantes-Pérez ${ }^{5}$ - Blanca Miriam Torres-Mendoza ${ }^{6} \cdot$ Clotilde Fuentes-Orozco $^{3} \cdot$ Kevin Josue Pintor-Belmontes ${ }^{3}$ - Bertha Georgina Guzmán-Ramírez ${ }^{3}$ - Aldo BernalHernández $^{3}$ - Alejandro González-Ojeda ${ }^{3}$ - Gabino Cervantes-Guevara ${ }^{1,6,7}$

1 Centro Universitario del Norte, Universidad de Guadalajara, Colotlán, Jalisco, Mexico

2 Sindicato Nacional de Trabajadores del Instituto Mexicano del Seguro Social, Sección III, Guadalajara, Jalisco, Mexico

3 Unidad de Investigación Biomédica 02, Hospital de Especialidades del Centro Médico Nacional de Occidente, Instituto Mexicano del Seguro Social, Guadalajara, Jalisco, Mexico

4 Departamento de Disciplinas Filosófico, Metodológicas e Instrumentales, Centro Universitario de Ciencias de la Salud, Universidad de Guadalajara, Guadalajara, Jalisco, Mexico

5 Departamento de Nutrición Clínica, Instituto Nacional de Ciencias Médicas y Nutrición "Salvador Zubirán", Ciudad de Mexico, Mexico

6 Departamento de Bienestar y Desarrollo Sostenible, Centro Universitario del Norte, Universidad de Guadalajara, Km. 191, México 45D No. 23, 46200 Colotlán, Jalisco, Mexico

7 Hospital Civil de Guadalajara "Fray Antonio Alcalde", Universidad de Guadalajara, Guadalajara, Jalisco, Mexico 